\title{
Overexpression of PTEN may increase the effect of pemetrexed on A549 cells via inhibition of the PI3K/AKT/mTOR pathway and carbohydrate metabolism
}

\author{
BO $\mathrm{LI}^{1 *}$, JUNKAI ZHANG ${ }^{2,3^{*}}, \mathrm{YA} \mathrm{SU}^{4 *}$, YILING HOU $^{5}, \mathrm{ZHENGUO} \mathrm{WANG}^{6}$, \\ LIN ZHAO ${ }^{7}$, SHENGKAI SUN $^{6}$ and $\mathrm{HAO} \mathrm{FU}^{8}$ \\ ${ }^{1}$ Department of Thoracic Medicine, Chest Hospital, Tianjin 300051; \\ ${ }^{2}$ Logistics University of Chinese People's Armed Police Force, Tianjin 300309; \\ ${ }^{3}$ Tianjin Key Laboratory of Cardiovascular Remodeling and Target Organ Injury, Pingjin Hospital; \\ ${ }^{4}$ Neurology Department, ${ }^{5}$ Physical Examination Center and ${ }^{6}$ Medical Research Department, Pingjin Hospital, Tianjin 300162; \\ ${ }^{7}$ Department of Geriatric Medicine, Fourth People's Hospital of Shanghai Affiliated to Tongji University School of Medicine, \\ Shanghai 200081; ${ }^{8}$ Department of Geriatric Medicine, Pingjin Hospital, Tianjin 300162, P.R. China
}

Received May 26, 2018; Accepted July 3, 2019

DOI: $10.3892 / \mathrm{mmr} .2019 .10617$

\begin{abstract}
Lung cancer is one of the leading causes of tumor-associated mortality, and $>75 \%$ of patients with lung cancer have non-small cell lung cancer (NSCLC). Pemetrexed, a folate antagonist, is a first-line chemotherapy drug for NSCLC that is administered alone or in combination with cisplatin. The present study established in vitro cell models of PTEN inhibition and overexpression, and the effects of the treatment with pemetrexed were investigated in these cell models. Result from the present study demonstrated that treatment with pemetrexed suppressed lung cancer cell proliferation, inhibited mRNA and protein expression levels of anti-apoptotic $\mathrm{Bcl} 2$, and increased the mRNA and the protein expression levels of pro-apoptotic p53 and apoptosis regulator BAX. The present study suggested that pemetrexed regulated apoptosis via the inhibition of the mTOR/PI3K/AKT signaling pathway. Additionally, cellular processes associated with the aerobic oxidation of carbohydrates were identified to be significantly inhibited. The present findings suggested that treatment with pemetrexed may exhibit synergistic effects with PTEN on
\end{abstract}

Correspondence to: Dr Lin Zhao, Department of Geriatric Medicine, Fourth People's Hospital of Shanghai Affiliated to Tongji University School of Medicine, 1878 North Sichuan Road, Hongkou, Shanghai 200081, P.R. China

E-mail: 784327180@qq.com

Dr Hao Fu, Department of Geriatric Medicine, Pingjin Hospital, 220 Chenglin Road, Tianjin 300162, P.R. China

E-mail: hao_fu2019@outlook.com

*Contributed equally

Key words: pemetrexed, non-small cell lung cancer, PTEN, carbohydrate metabolism lung cancer cells via the inhibition of the PI3K/AKT/mTOR signaling pathway and through carbohydrate metabolism, and treatment with pemetrexed combined with PTEN overexpression may represent a novel therapeutic strategy for the treatment of NSCLC.

\section{Introduction}

Lung cancer is one of the leading causes of tumor-associated mortality worldwide (1). Small cell lung cancer (SCLC) and non-small cell lung cancer (NSCLC) are the most common types of lung cancer, and NSCLC affects $\sim 80 \%$ of the total number of patients with lung cancer (2). NSCLC may be further classified into various subtypes, including squamous cell carcinoma, large cell carcinoma and adenocarcinoma, and each subtype exhibits particular characteristics. The majority of patients with NSCLC are diagnosed at late stages (primarily at stage IIIb and IV), and one-third of patients are diagnosed in the early stages of the disease (3). The prognosis of patients with NSCLC remains poor, and the average survival rate is 8-10 months, with a 5-year survival rate of $\sim 15 \%$ (4). Numerous treatments are available to control NSCLC growth and metastasis, including surgery, radiation therapy, chemotherapy and targeted therapy, and various treatments exhibit positive results on NSCLC cells in vitro (5).

Pemetrexed is a first-line standard treatment for NSCLC (6). Previous studies demonstrated that treatment with pemetrexed alone or in combination with other chemotherapeutics may prolong the overall survival of patients with NSCLC, and pemetrexed has limited toxicity in humans (7). The toxic effects following treatment with pemetrexed were identified to primarily affect the immune, hematopoietic and digestive systems; however, overall toxicity is decreased compared with other chemotherapeutics (8). Pemetrexed was demonstrated to have antitumor activity primarily via the inhibition of thymidylate synthase, dihydrofolate reductase and glycinamide ribonucleotide formyl transferase (9). In 
addition, 5-aminoimidazole-4-carboxamide ribonucleotide formyltransferase is involved in the antitumor activity of pemetrexed (9). PTEN, located on chromosome 10q23, is able to suppress the proliferation of multiple types of cancer (10). Although PTEN mediates the phosphorylation of various proteins, one of the most common substrates of PTEN is phosphatidylinositol-3,4,5-triphosphate (PIP3) (11). PIP3 is a second messenger involved in intracellular signaling pathways that, following phosphorylation by PTEN at position D3, is able to directly inhibit the activity of PI3K, thus negatively regulating the PI3K/AKT signaling pathway (12). The PIP3/PI3K/AKT signaling pathway regulates cellular metabolism, cell proliferation and migration (13), important processes involved in tumor development and progression. Human cancer may exhibit dysfunctions and mutations in PTEN, and its promoter was identified to be hypermethylated in various types of cancer, resulting in the silencing of PTEN and subsequent activation of the PI3K/AKT signaling pathway, thus promoting tumor growth and migration (14). In addition, a previous study identified that dysfunctions of PTEN were associated with drug resistance in human tumors (15). The invasive and metastatic ability of tumors increased significantly following dysregulation of PTEN (16). However, the detailed molecular mechanisms underlying the anti-tumor activity of PTEN and pemetrexed remain unclear, and whether the overexpression of PTEN is able to increase the anticancer activity of pemetrexed in NSCLC has not been previously investigated, to the best of the authors' knowledge.

In the present study, the antitumor activity of pemetrexed was demonstrated to increase following PTEN overexpression. The combination of pemetrexed with PTEN overexpression inhibited the AKT signaling pathway and activated the mTOR signaling pathway, thus promoting the upregulation of apoptosis-associated genes at the transcriptional and protein levels. In addition, treatment with pemetrexed combined with PTEN overexpression downregulated the expression of enzymes associated with the aerobic oxidation of carbohydrates.

\section{Materials and methods}

Reagents and materials. FBS (cat. no. 10100147), high glucose Dulbecco's Modified Eagle Medium (H-DMEM; cat. no. 11995065) and GlutaMAX ${ }^{\mathrm{TM}}$ (cat. no. 25030081) were purchased from Gibco ${ }^{\circledR}$ (Thermo Fisher Scientific, Inc.). Penicillin-streptomycin (cat. no. P1400) and the MTT Assay kit (cat. no. M1020) were purchased from Beijing Solarbio Science \& Technology Co., Ltd. EcoRI (cat. no. R0101L) and XhoI (cat. no. R0146L) were purchased from New England BioLabs, Inc. Hieff Trans ${ }^{\mathrm{TM}}$ transfection reagent (cat. no. 40802ES01) and G418 ${ }^{\circledR}$ (cat. no. 60220ES03) were purchased from Yeasen Biotechnology Co., Ltd. The chemical inhibitor of PTEN, SF1670 (cat. no. S7310), was purchased from Selleck Chemicals. Pemetrexed (cat. no. CDS024404) was purchased from Sigma-Aldrich (Merck KGaA). SuperRT One Step RT-PCR Kit (cat. no. CW0742), RNApure Tissue \& Cell kit (cat. no. CW0584), HiFiScript cDNA Synthesis kit (cat. no. CW2569) and Super TaqMan OneStep reverse transcription-quantitative PCR (RT-qPCR) kit (cat. no. CW2695) were purchased from CoWin Biosciences Co., Ltd. The primary antibodies for malate dehydrogenase 1 (MDH1; cat. no. ab175455), succinate-Coenzyme A (CoA) ligase GDP-forming beta subunit (SUCLG2; cat. no. ab187996), aconitase 2 (ACO2; cat. no. ab110321), p53 (cat. no. ab26), proliferating cell nuclear antigen (PCNA; cat. no. ab29), ERK (cat. no. ab54230), phosphorylated (p-)ERK (cat. no. ab50011), AKT (cat. no. ab8805), p-AKT (cat. no. ab38449), mTOR (cat. no. ab2732), p-mTOR (cat. no. ab109268) and GAPDH (cat. no. ab181602); Donkey anti goat (cat. no. ab97120), goat anti rabbit (cat. no. ab97080) and goat anti-mouse (cat. no. ab97040) secondary antibodies were purchased from Abcam. A549 lung adenocarcinoma cells (cat. no. SCSP-503) were purchased from Cell library of typical culture preservation committee of the Chinese Academy of Science.

Vector construction. RNA of A549 cells were extracted according to the protocol of RNApure Tissue \& Cell kit. The full-length coding sequence of PTEN was cloned following PCR from A549 cells using SuperRT One Step RT-PCR kit with the following primers: Forward, 5'-CGGAATTCGGATGTCCCG AAAGCAGG-3', reverse 5'-CCGCTCGAGTCAGATGTTGAG CGG-3'. The reaction mixture was made up as recommended by the manufacturer of the kit, and the reaction steps were: Reverse transcription at $45^{\circ} \mathrm{C}$ for $30 \mathrm{~min}$ and pre-degeneration at $95^{\circ} \mathrm{C}$ for $2 \mathrm{~min}$ repeated for 40 cycles: Degeneration at $94^{\circ} \mathrm{C}$ for $30 \mathrm{sec}$, annealing at $58^{\circ} \mathrm{C}$ for $30 \mathrm{sec}$, extension at $72^{\circ} \mathrm{C}$ for $30 \mathrm{sec}$. Followed with final extension at $72^{\circ} \mathrm{C}$ for $5 \mathrm{~min}$. The PCR product and the pcDNA3.1-3XFlag vector (MJ8001, Mingjing Biology) were digested with two restriction enzymes, EcoRI and XhoI. Following digestion, the DNA fragment containing the coding sequence was cloned into the vector to construct the expression plasmid pcDNA3.1-3XFlag-PTEN. A549 cells were transfected with $10 \mu \mathrm{g}$ pcDNA3.1-3XFlag-PTEN or the empty plasmid at $37^{\circ} \mathrm{C}$ using Hieff Trans ${ }^{\mathrm{TM}}$ transfection reagent for $48 \mathrm{~h}$, according to the manufacturer's protocol. Subsequently, cells with stable PTEN overexpression were selected by treating transfected cells with $1 \mathrm{mg} / \mathrm{ml} \mathrm{G} 418$ at $37^{\circ} \mathrm{C}$ until stable expressed cells were successfully constructed.

MTT assay. MTT assay was performed according to a previous study (17). Cells were cultured in 96-well plates at a concentration of $1 \times 10^{4}$ cells/well. Cultures at $80-85 \%$ confluence were treated with pemetrexed at various concentrations $(0,5,10$ and $20 \mu \mathrm{g} / \mathrm{ml}$ ). Following a 24-h incubation, cells were washed with sterile PBS to remove extra pemetrexed. MTT was diluted in the medium at a concentration of $5 \mathrm{mg} / \mathrm{ml}$, and incubated with the cells for $4 \mathrm{~h}$. Following incubation, DMSO was added to each well and the optical density (OD) at $560 \mathrm{~nm}$ was determined using a microplate reader. The viability of cells was calculated using the following formula: $\left(\mathrm{OD}_{\text {Experiment }}-\mathrm{OD}_{\mathrm{Blank}}\right) /$ $\left(\mathrm{OD}_{\text {Control}}-\mathrm{OD}_{\text {Blank }}\right) \times 100 \%$.

Cell culture and grouping. Cells were cultured in H-DMEM supplemented with $10 \%$ FBS and GlutaMAX ${ }^{\mathrm{TM}}(2 \mathrm{mmol} / \mathrm{l})$ in a humid atmosphere with $5 \% \mathrm{CO}_{2}$ at $37^{\circ} \mathrm{C}$. Cells were divided into six groups: i) Negative control (NC) group; ii) treatment with $10 \mathrm{mg} / \mathrm{ml}$ pemetrexed for $24 \mathrm{~h}(\mathrm{NC}+\mathrm{P})$ group; iii) PTEN inhibition ( $2 \mu \mathrm{mol} / 1$ for $36 \mathrm{~h}$ ) (PI) group; iv) PTEN inhibition $(2 \mu \mathrm{mol} / \mathrm{l}$ for $36 \mathrm{~h})$ with treatment with $10 \mathrm{mg} / \mathrm{ml}$ pemetrexed for $24 \mathrm{~h}(\mathrm{PI}+\mathrm{P})$ group; v) PTEN overexpression (PO) group; and vi) PTEN overexpression with treatment with $10 \mathrm{mg} / \mathrm{ml}$ 

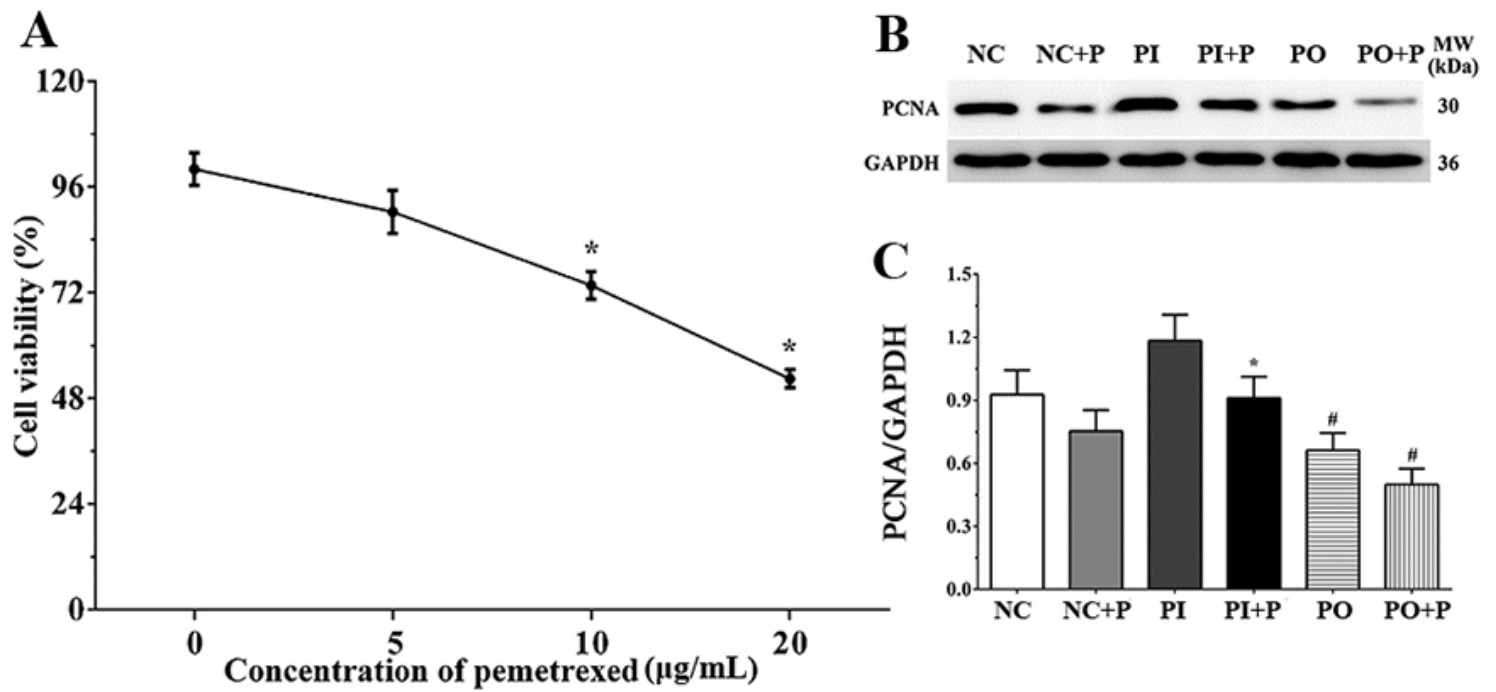

Figure 1. Effects of pemetrexed on the proliferation of A549 cells. (A) Dose-dependent effect of pemetrexed on the proliferation of A549 cells, as measured by MTT assay. " $\mathrm{P}<0.05$ vs. untreated control group. (B) Protein expression level of PCNA in each group, as detected by western blotting. (C) Quantification analysis of western blotting. Data are presented as the mean \pm standard deviation $(\mathrm{n}=3)$. GAPDH was used as the internal control. ${ }^{*} \mathrm{P}<0.05$ vs. Inhibitor; ${ }^{*} \mathrm{P}<0.05$ vs. NC group. MW, molecular weight; P, pemetrexed; PCNA, proliferating cell nuclear antigen.

pemetrexed for $24 \mathrm{~h}(\mathrm{PO}+\mathrm{P})$ group. Following treatment, the cells were washed with sterile PBS to remove residual pemetrexed and collected for use in further experiments.

RNA extraction and RT. RNA extraction was performed using the RNApure Tissue \& Cell kit according to the manufacturer's protocol. Cells were lysed, incubated for $5 \mathrm{~min}$ at room temperature, and centrifuged at 14,462 x g for $5 \mathrm{~min}$. Ethanol was added and the mixture was loaded onto the adsorption columns provided in the kit. RNA was eluted using RNase-free water following washing with wash buffer provided in the kit. The concentration of extracted RNA was measured using the Nanodrop ND-2000 (Thermo Fisher Scientific, Inc.). An equal amount of RNA from each group was used as template to perform RT. The reaction solution was prepared according to the manufacturer's protocol. The reaction solution was mixed and incubated at $42^{\circ} \mathrm{C}$ for $15 \mathrm{~min}$, followed by an incubation at $85^{\circ} \mathrm{C}$ for $5 \mathrm{~min}$.

$q P C R$. Primers used for qPCR were: $\mathrm{p} 53$, forward 5'-ATTAGC GGCCGATGGAGGAGCCGC-3', reverse 5'-ATCTCGAGT CAGTCTGAGTCAGGCCC-3'; Bcl, forward 5'-CGACGA CTTCTCCCGCCGCTACCGC-3', reverse 5'-CCGCATGCT GGGGCCGTACAGTTCC-3'; BAX, forward 5'-TGCAGA GGATGATTGCTGAC-3', reverse 5'-GAGGACTCCAGC CACAAAGA-3'; GAPDH, forward 5'-GAATCTCACTCA GACGAGGACTT-3', reverse 5'-GGTGTGTGGTTTAAG TGATGTCA-3'. qPCR was performed according to the manufacturer's protocol, and the thermocycling conditions were as follows: 40 cycles at $95^{\circ} \mathrm{C}$ for $15 \mathrm{sec}$ and at $60^{\circ} \mathrm{C}$ for $40 \mathrm{sec}$. The threshold cycle value was calculated using the intensity of the fluorescence signal following PCR amplification (18). GAPDH was used as the internal reference, and the quantification result for each target gene was normalized to GAPDH.

Western blotting. Cells from each group were washed with PBS and were lysed with RIPA buffer supplied with protease inhibitor cocktail (CW2383, CWbio). Following lysis, the supernatant was collected following centrifugation at $14,462 \mathrm{x} \mathrm{g}$ for $10 \mathrm{~min}\left(4^{\circ} \mathrm{C}\right)$ and a bicinchoninic acid assay was used to measure the concentration of protein. Same amounts $(60 \mu \mathrm{g})$ of protein from each group were used to perform $10 \%$ SDS-PAGE electrophoresis. Following electrophoresis, proteins were transferred onto $0.22-\mu \mathrm{m}$-thick nitrocellulose membranes using a semi-dry electro blotter. Membranes were blocked with 5\% skimmed milk at room temperature for $1 \mathrm{~h}$, and subsequently incubated with the primary antibody $(1: 1,000)$ at $4^{\circ} \mathrm{C}$ overnight, followed by incubation with the secondary antibody $(1: 5,000)$ for $1 \mathrm{~h}$ at room temperature. Chemiluminescence was performed using electrochemiluminescence reagent (WBKLS0500, Merck KGaA) to detect the protein expression levels. The densitometric analysis was performed using Scion Image (version 4.0.3.2; Scion Corporation) software and normalized to GAPDH.

Statistical analysis. Data are presented as the mean \pm standard deviation. Each experiment was repeated three times. One-way ANOVA was performed to assess differences among groups followed by Tukey's post hoc test for multiple comparisons. GraphPad (version 7; GraphPad Software, Inc., La Jolla, CA, USA) was used to analyze the data. $\mathrm{P}<0.05$ was considered to indicate a statistically significant difference.

\section{Results}

Effects of pemetrexed on the proliferation of A549 cells. MTT assay results suggested that the proliferation of A549 cells was inhibited with pemetrexed in a dose-dependent manner (Fig. 1A). Following treatment with $5 \mathrm{mg} / \mathrm{ml}$ pemetrexed for $24 \mathrm{~h}$, the cell viability was $90.30 \pm 4.86 \%$, with $10 \mathrm{mg} / \mathrm{ml}$ pemetrexed was $73.60 \pm 3.12 \%$ and with $20 \mathrm{mg} / \mathrm{ml}$ was $52.40 \pm 2.10 \%$. Pemetrexed was able to significantly inhibit the viability of A549 cells at the concentrations of $10 \mathrm{mg} / \mathrm{ml}$ and $20 \mathrm{mg} / \mathrm{ml}$. Therefore, $10 \mathrm{mg} / \mathrm{ml}$ was used as the working 

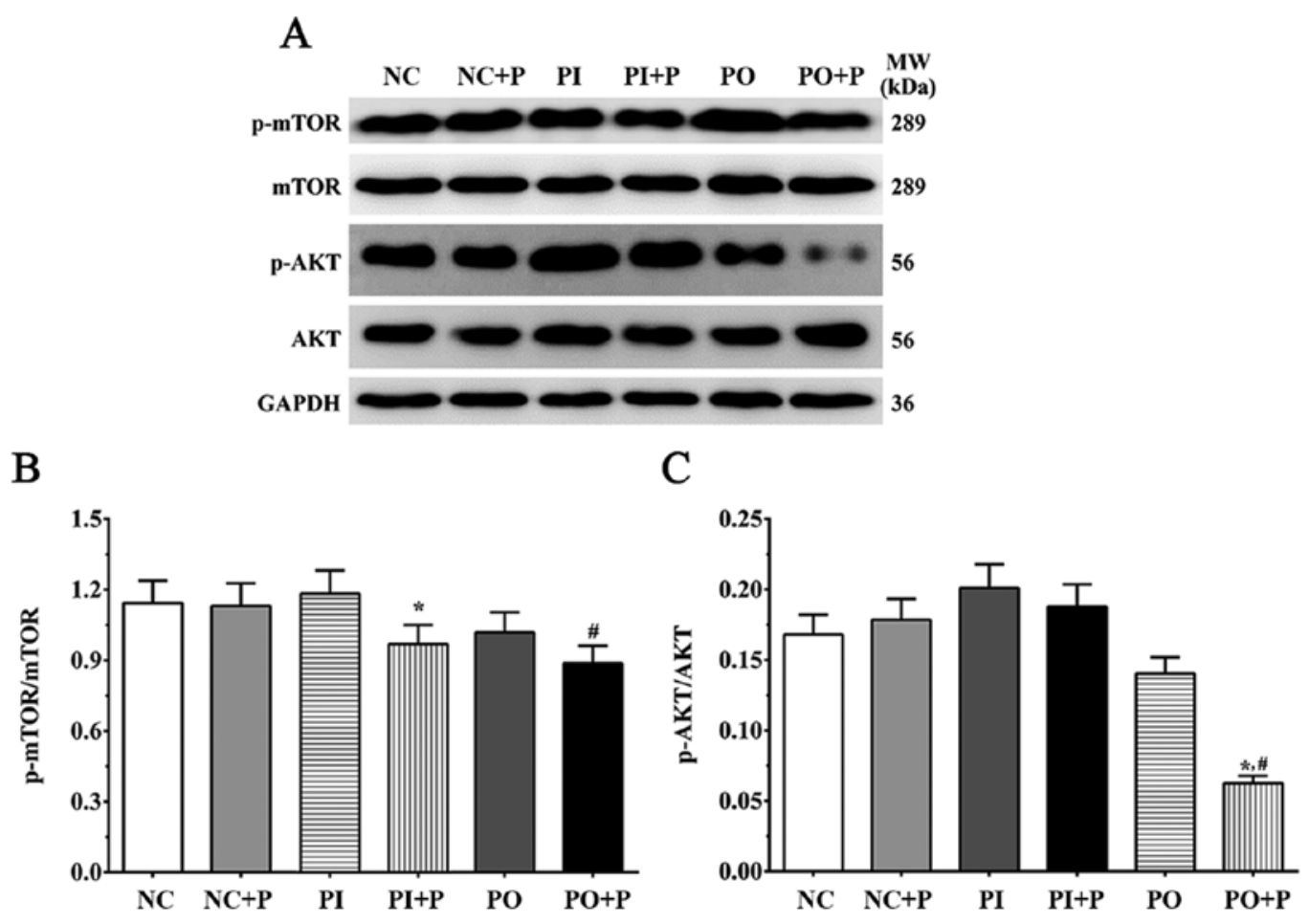

Figure 2. Effects of pemetrexed on the AKT/mTOR signaling pathway. (A) Protein expression levels of p-mTOR, mTOR, p-AKT and AKT, as detected by western blotting. Quantification of (B) p-mTOR/mTOR and (C) p-AKT/AKT ratios. GAPDH was used as the internal control. Data are presented as the mean \pm standard deviation $(\mathrm{n}=3)$. ${ }^{*} \mathrm{P}<0.05$ vs. corresponding control group without pemetrexed treatment; ${ }^{\text {}} \mathrm{P}<0.05$ vs. NC group. MW, molecular weight; $\mathrm{P}$, pemetrexed; p-, phosphorylated.

concentration for pemetrexed in the following experiments, since this concentration was the lowest to significantly inhibit the proliferation of A549 cells. PCNA regulates the replication of DNA, Notably, the protein expression level of PCNA decreased following treatment with pemetrexed (Fig. 1B); however, this decrease was not statistically significant in the single pemetrexed treatment group (Fig. 1C). The protein expression level of PCNA was significantly decreased in the $\mathrm{PI}+\mathrm{P}$ group compared with the PI group. In addition, the protein expression levels of PCNA in the PO and in the PO $+\mathrm{P}$ groups were significantly decreased compared with the $\mathrm{NC}$ group.

Protein expression levels of factors of the AKT/mTOR signaling pathway. The protein expression ratios of p-AKT/AKT and p-mTOR/mTOR were measured by western blotting and densitometric analysis (Fig. 2). The p-mTOR/mTOR ratio was slightly decreased following treatment with pemetrexed, and was significantly decreased in the PI $+\mathrm{P}$ and the $\mathrm{PO}+$ $\mathrm{P}$ groups compared with the PI and the NC groups, respectively (Fig. 2). The p-AKT/AKT ratio was also measured, and the protein expression levels presented a trend similar to the $\mathrm{p}-\mathrm{mTOR} / \mathrm{mTOR}$ ratio. Single inhibition or overexpression did not significantly change the ratio of p-AKT/AKT in these groups, and the p-AKT/AKT ratio was not significantly affected in the $\mathrm{NC}+\mathrm{P}$ or $\mathrm{PI}+\mathrm{P}$ groups compared with the corresponding control group without pemetrexed treatment; however, it was slightly decreased in the PO group and was significantly decreased in the $\mathrm{PO}+\mathrm{P}$ group compared with the NC group (Fig. 2).
Alterations in the $m R N A$ and the protein expression levels of apoptosis-associated factors. The protein expression level of p53 was significantly increased in the $\mathrm{NC}+\mathrm{P}$ group compared with the NC group (Fig. 3A and B). Following treatment with PTEN inhibitor, the protein expression level of p53 in the PI group was significantly decreased compared with the NC group. The protein expression level of p53 in the PI + P group was significantly increased compared with the PI group, and significantly increased in the $\mathrm{PO}$ and $\mathrm{PO}+\mathrm{P}$ groups compared with the $\mathrm{NC}$ groups. In addition, the protein expression levels of $\mathrm{Bcl} 2$ and $\mathrm{BAX}$ were detected in each group (Fig. 3A). The protein expression level of Bcl2 was slightly decreased following treatment with pemetrexed in the $\mathrm{NC}+\mathrm{P}$ group (Fig. 3C); however, the protein expression level of Bcl2 was not significantly increased in PI + P group, and was significantly decreased in the $\mathrm{PO}+\mathrm{P}$ group compared with the $\mathrm{PO}$ group. In addition the protein expression level of $\mathrm{Bcl} 2$ was significantly decreased in the PO group compared with the NC group. The protein expression level of BAX was slightly increased following treatment with pemetrexed and was significantly increased in the PI $+\mathrm{P}$ and $\mathrm{PO}+\mathrm{P}$ groups compared with the PI and the PO groups, respectively (Fig. 3D). Compared with NC group, the expression level of BAX was significantly decreased following inhibition of PTEN. The expression of PTEN was detected using PCR. Pemetrexed significantly increased the expression of PTEN compared with inhibitor group. The expression of PTEN was significantly decreased in inhibitor group and significantly increased in $\mathrm{PO}$ and $\mathrm{PO}+\mathrm{P}$ group compared with NC group. The mRNA expression levels of p53, BAX and Bcl2 were also measured. The expression of 


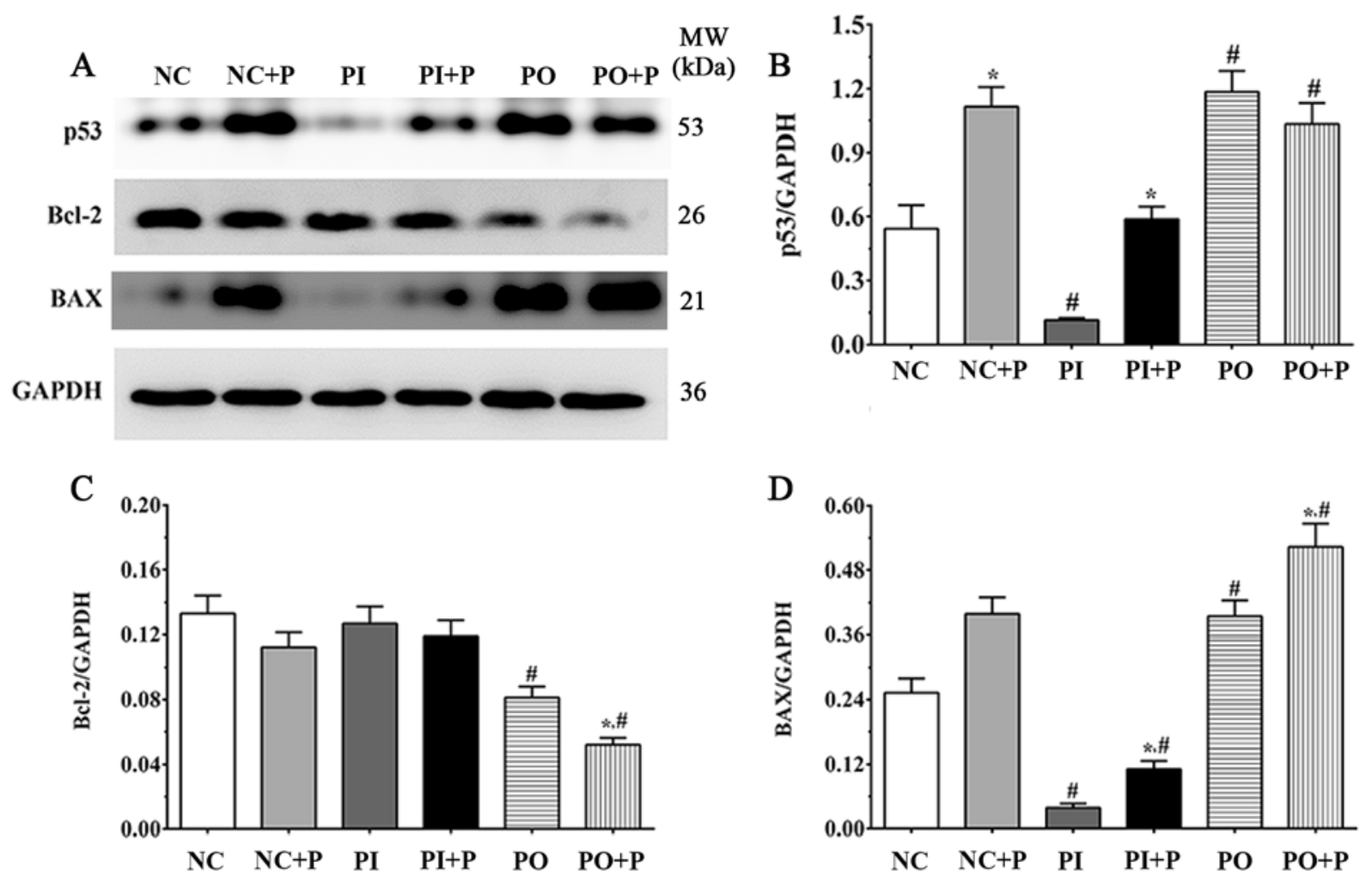

Figure 3. Effects of pemetrexed on the protein expression level of apoptosis-associated factors. (A) Protein expression levels of p53, Bcl2 and BAX, as detected by western blotting. Quantification of the protein expression levels of (B) p53, (C) Bcl2 and (D) BAX. GAPDH was used as the internal control. Data are presented as the mean \pm standard deviation $(\mathrm{n}=3)$. ${ }^{*} \mathrm{P}<0.05$ vs. corresponding control group without pemetrexed treatment; ${ }^{*} \mathrm{P}<0.05$ vs. NC group. MW, molecular weight; $P$, pemetrexed.

A

舀

$\mathrm{C}$

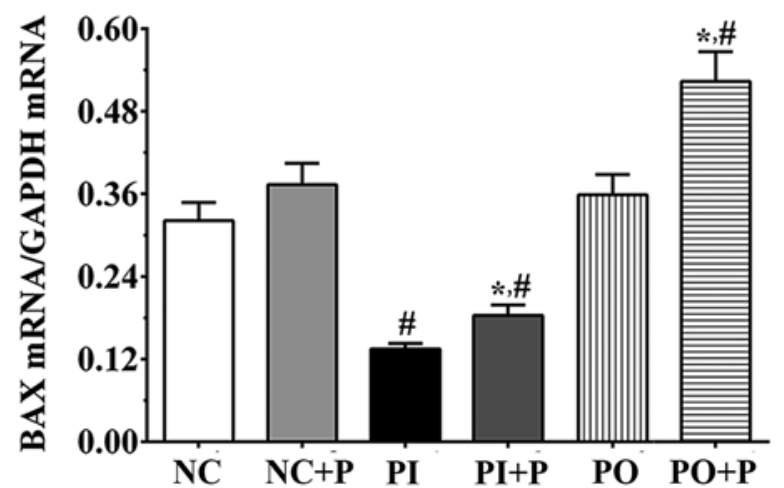

B

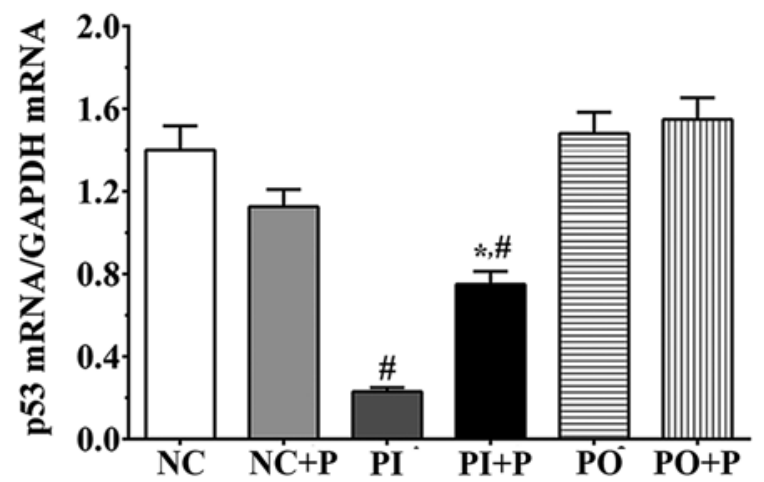

D

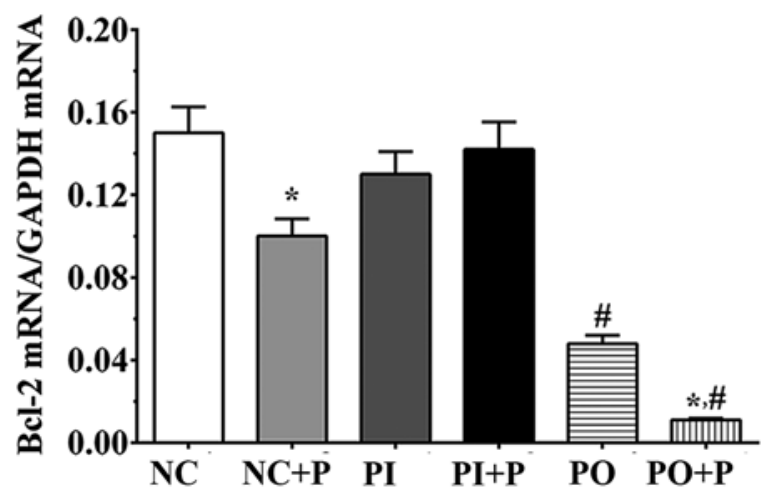

Figure 4. Effects of pemetrexed on the expression levels of apoptosis-associated factors. Quantification of the mRNA expression levels of (A) PTEN, (B) p53, (C) Bcl2 and (D) BAX, as measured by reverse transcription-quantitative polymerase chain reaction. GAPDH was used as the internal control. Data are presented as the mean \pm standard deviation $(n=3)$. ${ }^{*} \mathrm{P}<0.05$ vs. corresponding control group without pemetrexed treatment; ${ }^{\#} \mathrm{P}<0.05$ vs. NC group. $\mathrm{P}$, pemetrexed. 
A

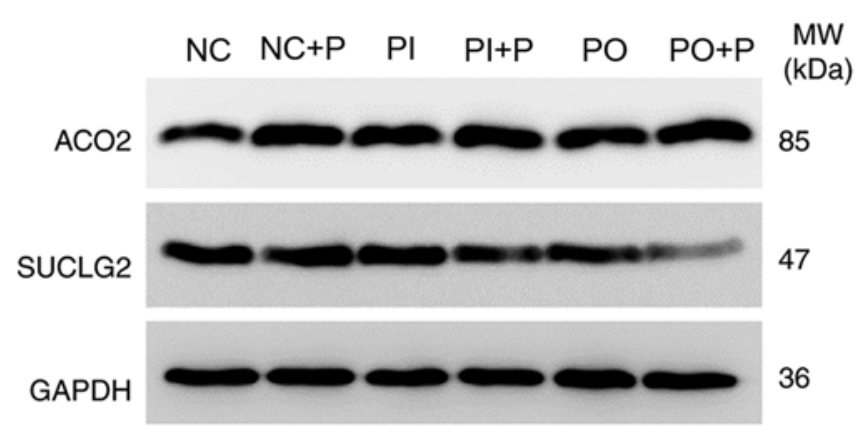

B

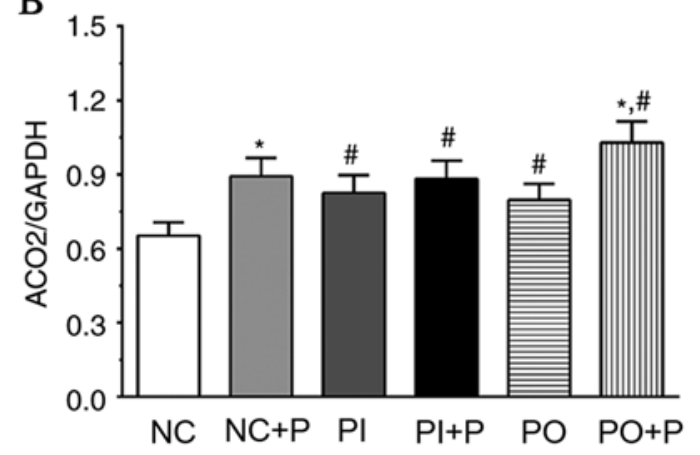

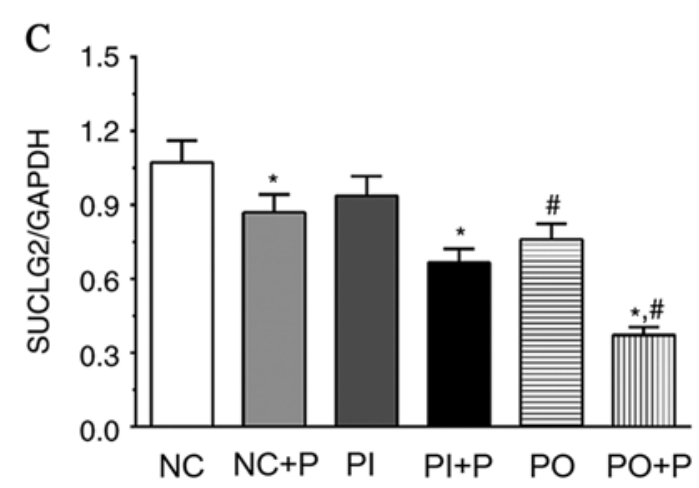

Figure 5. Effects of pemetrexed on the protein expression levels of enzymes involved in the tricarboxylic acid cycle. (A) Protein expression levels of ACO2 and SUCLG2 in each group, as measured by western blotting. Quantification of the protein expression level of (B) ACO2 and (C) SUCLG2. GAPDH was used as the internal control. Data are presented as the mean \pm standard deviation $(n=3) .{ }^{*} \mathrm{P}<0.05$ vs. corresponding control group without pemetrexed treatment; ${ }^{\#} \mathrm{P}<0.05$ vs. NC group. ACO2, aconitase 2; MW, molecular weight; P, pemetrexed; SUCLG2 succinate-Coenzyme A ligase GDP-forming beta subunit.

p53 was significantly decreased in inhibitor group and $\mathrm{PI}+\mathrm{P}$ group compared with the NC group, and pemetrexed significantly increased the expression of PTEN compared with the inhibitor group. Pemetrexed significantly increased the expression of $\mathrm{BAX}$ in $\mathrm{PO}+\mathrm{P}$ and $\mathrm{PI}+\mathrm{P}$ group compared with the $\mathrm{PO}$ and PI groups, and significantly decreased in inhibitor and $\mathrm{PI}+\mathrm{P}$ group compared with the $\mathrm{NC}$ group, and significantly increased in $\mathrm{PO}+\mathrm{P}$ group compared with the $\mathrm{NC}$ group. Pemetrexed significantly decreased the expression of Bcl-2 in $\mathrm{NC}+\mathrm{P}$ and $\mathrm{PO}+\mathrm{P}$ group compared with $\mathrm{NC}$ and $\mathrm{PO}$ groups, and significantly decreased in $\mathrm{PO}$ and $\mathrm{PO}+\mathrm{P}$ groups compared with the NC group (Fig. 4). The present qPCR and western blot results suggested that the expression levels of apoptosis-associated factors were altered at the transcriptional and the protein levels.

Protein expression levels of proteins associated with carbohydrate metabolism following treatment with pemetrexed. The protein expression levels of ACO2 and SUCLG2 were significantly altered following treatment with pemetrexed (Fig. 5). The protein expression level of ACO2 was significantly increased in the $\mathrm{NC}+\mathrm{P}$ and $\mathrm{OP}+\mathrm{P}$ groups compared with the NC and OP groups, respectively, and was significantly increased in the PI, PI+P and PO groups compared with the NC group. However, the protein expression level of SUCLG2 exhibited an opposite trend. Pemetrexed significantly decreased the protein expression level of SUCLG2 in $\mathrm{NC}+\mathrm{P}$, $\mathrm{PI}+\mathrm{P}$ and $\mathrm{PO}+\mathrm{P}$ groups compared with the NC, $\mathrm{PI}$ and $\mathrm{PO}$ groups, respectively. In addition, the protein expression level of SUCLG2 was significantly decreased in the $\mathrm{PO}$ and $\mathrm{PO}+\mathrm{P}$ group compared with the NC group.

\section{Discussion}

Lung cancer is one of the leading causes of tumor-associated mortalities in men and women worldwide (19). In 2015, the guidelines of The American Society of Clinical Oncology recommended two drugs for the treatment of NSCLC, docetaxel and pemetrexed (20). The present study established in vitro models of PTEN inhibition and overexpression, and the present results suggested that pemetrexed was able to suppress the proliferation of A549 cells by inhibiting the $\mathrm{PI} 3 \mathrm{~K} / \mathrm{AKT} / \mathrm{mTOR}$ signaling pathway and the carbohydrate metabolism, inducing apoptosis in A549 cells and exerting anti-tumor activities. In the present study, PTEN overexpression was identified to increase the effects of pemetrexed on lung cancer cells, enhance the anti-tumor effect of pemetrexed. A previous studies demonstrated that pemetrexed regulated the activity of the PTEN/PI3K/AKT/mTOR pathway indirectly (21), and further experiments are required to confirm the mechanism observed in the present study.

PTEN is a tumor suppressor gene, and is able to limit the aggressiveness of kidney, breast and prostate cancers by regulating cell proliferation exerting lipid phosphatase activity (22). The phosphatase activity of PTEN was identified in the C-terminal region of the protein (23), and the phosphorylation state of PTEN affects the intramolecular partners of PTEN, altering its subcellular localization and phosphatase 
activity (24). Mutations in the active site of PTEN are associated with the loss of its lipid phosphatase activity, and are identified in various types of human cancer (25). The PI3K/PTEN/AKT signaling axis is associated with cell proliferation, and dysfunctions or mutations of its components may lead to abnormal cell growth and tumor development (26). Activation of the $\mathrm{PI} 3 \mathrm{~K} / \mathrm{AKT}$ pathway was identified in various types of cancer and is associated with tumor progression and with poor prognosis of patients with cancer. As a downstream molecular factor of the PI3K/AKT pathway, the activity of mTOR is associated with cancer (27). A previous study identified that inhibition of mTOR was able to increase the anti-tumor effect of pemetrexed by inhibiting autophagy in NSCLC cells (28). In the present study, the activity of the PI3K/mTOR signaling pathway was not significantly changed following single pemetrexed treatment, although the effect increased following PTEN overexpression. The present results suggested that pemetrexed may inhibit the growth of A549 cells by inhibiting the PI3K/AKT/mTOR signaling pathway, and inhibition of PTEN may increase the effect of pemetrexed, whereas, PTEN overexpression may decrease pemetrexed activity.

$\mathrm{BAX}, \mathrm{Bcl} 2$ and $\mathrm{p} 53$ are downstream molecules of the $\mathrm{PI} 3 \mathrm{~K} / \mathrm{AKT} / \mathrm{mTOR}$ pathway, and serve important role in apoptosis. In normal tissue, p53 is involved in various biological processes, including the regulation of cell cycle, homeostasis and apoptosis (29). Notably, mutations in p53 lead to cancer development, and the transcription factor p53 was identified to be mutated in $>50 \%$ of patients with cancer (30). Additionally, a previous study demonstrated that the expression of $\mathrm{p} 53$ is silenced in human cancer tissues (31). Therefore, p53 is considered the 'guardian of the genome' (32). PTEN was identified to directly interact with $\mathrm{p} 53$, and decreases the degradation of p53 by regulating MDM2 proto-oncogene, thus increasing the protein expression level of p53 (33). The expression level of $\mathrm{Bcl} 2$ binding component 3 (BBC3) was identified to be promoted by $\mathrm{p} 53$, and $\mathrm{BBC} 3$ may be able to interact with $\mathrm{Bcl} 2$ or $\mathrm{Bcl} 2$ like 1 via its $\mathrm{Bcl} 2$ homology 3 domain, thus inducing the expression of BAX (34). Additionally, p53 was demonstrated to be able to upregulate the expression level of BAX via the TNF receptor superfamily member 10b/Fas-associated via death domain pathway (35). The present results suggested that pemetrexed may increase the expression level of p53 following inhibition of PTEN, thus suggesting that pemetrexed may inhibit the proliferation of A549 cells by regulating p53 at the protein and transcriptional levels. $\mathrm{BAX}$, a tumor suppressor protein, belongs to the $\mathrm{Bcl} 2$ family and serves an important role in the intrinsic apoptosis pathway (36). Upon activation, BAX translocates on the outer membrane of mitochondria following apoptotic stimuli, and this translocation is a crucial step in the initiation of apoptosis (37). In addition, BAX may be directly activated by p53 (38). BAX promotes the release of cytochrome $\mathrm{c}$ from the mitochondria and activate multiple caspases, thus inducing apoptosis in cancer cells (39). In the present study, treatment with pemetrexed was able to increase the expression of BAX at the protein and transcriptional levels, and overexpression of PTEN increased this effect, whereas, inhibition of PTEN led to the opposite effect.

$\mathrm{Bcl} 2$ is an anti-apoptotic member of the Bcl 2 family (40), and overexpression of anti-apoptotic molecules of the $\mathrm{Bcl} 2$ family including $\mathrm{Bcl} 2$ and $\mathrm{Bcl} 2$-like 1 is frequently observed in human tumor tissues (41). Overexpression of $\mathrm{Bcl} 2$ was identified to be associated with cancer occurrence and progression, and chemotherapy resistance (42). Various small molecule inhibitors of $\mathrm{Bcl} 2$ have been investigated in the treatment of hematological cancer (43). In contrast with the effects of pemetrexed on BAX, pemetrexed decreased the expression level of $\mathrm{Bcl} 2$ at the protein and transcriptional levels, and PTEN overexpression increased this effect. Collectively, treatment with pemetrexed was able to promote apoptosis in cancer cells, inhibiting the anti-apoptotic factors BAX and p53, thus exerting anti-tumor activity. Notably, the expression level of PTEN was associated with pemetrexed activity, and overexpression of PTEN increased the anti-tumor effects of pemetrexed.

Rapid cell proliferation is a characteristic of cancer cells; in order to sustain their metabolic requirements, multiple metabolic alterations occur in cancer cells (44), including the increased uptake of nutrients and the preferential use of glucose as carbon source (45), resulting in an increased metabolic rate. Carbohydrate metabolism is an important pathway used by cancer cells to sustain their proliferation during tumor development (46). The tricarboxylic acid (TCA) cycle is a central hub in the catabolism of carbohydrates, and it is involved in various physiological processes. Previous studies identified that the TCA cycle in cancer cells may be uncoupled to glycolysis to allow the use of additional carbon sources, including glutamine, to fulfill their metabolic requirements $(45,47)$. Therefore, in the present study, it was hypothesized that the expression level of factors associated to the aerobic oxidation of glucose, including enzymes of the TCA cycle, may be altered following treatment with pemetrexed. ACO2 and SUCLG2 are important enzymes of the TCA cycle. ACO2 is able to reversibly catalyze citrate into isocitrate forming a cis-aconitate intermediate, and SUCLG2 is a subunit of the succinyl-CoA synthetase, which is able to reversibly catalyze the formation of succinyl-CoA into succinate. Treatment with pemetrexed led to inverse effects on ACO and SUCLG2, the protein expression level of ACO2 increased and the protein expression level of SUCLG2 decreased. This effect was increased following PTEN overexpression and decreased following PTEN inhibition. The present results suggested that pemetrexed may exert an anti-tumor activity via the inhibition of the TCA cycle, decreasing the energy supply of cancer cells and inducing apoptosis. The effects of pemetrexed were altered following PTEN inhibition or overexpression, suggesting that PTEN overexpression may enhance the anti-tumor effect of pemetrexed, and may contribute to the development of a novel therapeutic strategy in the future.

In the present study, pemetrexed was demonstrated to inhibit the proliferation of lung cancer cells via the inhibition of the PI3K/AKT/mTOR signaling pathway and the upregulation of pro-apoptotic factors at the protein and transcriptional levels. Furthermore, the results suggested that pemetrexed may inhibit the aerobic oxidation of glucose, decreasing the energy supply of cancer cells, leading to apoptosis. In the present in vitro model, and PTEN overexpression was able to increase the effect of pemetrexed on lung cancer cells. The modulation of PTEN, in combination with pemetrexed, may represent a therapeutic strategy against NSCLC. However, the present study presents certain limitations, since only one cell line was examined, and further in vitro and clinical experiments are required to be performed in future studies, including knockdown of PTEN via small interfering RNA technology. 


\section{Acknowledgements}

Not applicable.

\section{Funding}

The present study was supported by The Tianjin Science and Technology Planning Project (grant no. 16ZXHLSY00120).

\section{Availability of data and materials}

The datasets used and/or analyzed during the current study are available from the corresponding author on reasonable request.

\section{Authors' contributions}

$\mathrm{BL}, \mathrm{JKZ}$ and $\mathrm{YS}$ performed the experiment and wrote the manuscript. YLH and ZGW designed the experiment. LZ, HF and SKS revised the manuscript and analyzed the data. All authors read and approved the manuscript and agree to be accountable for all aspects of the research in ensuring that the accuracy or integrity of any part of the work are appropriately investigated and resolved.

\section{Ethics approval and consent to participate}

Not applicable.

\section{Patient consent for publication}

Not applicable.

\section{Competing interests}

The authors declare that they have no competing interests.

\section{References}

1. Park S, Keam B, Kim SH, Kim KH, Kim YJ, Kim JS, Kim TM, Lee SH, Kim DW, Lee JS and Heo DS: Pemetrexed singlet versus nonpemetrexed-based platinum doublet as second-line chemotherapy following first-line epidermal growth factor receptor (EGFR) tyrosine kinase inhibitor failure in non-small cell lung cancer patients with EGFR mutations. Cancer Res Treat 47: 630-637, 2015.

2. Masuda T, Imai H, Kuwako T, Miura Y, Yoshino R, Kaira K, Shimizu K, Sunaga N, Tomizawa Y, Ishihara S, et al: Effcacy of platinum combination chemotherapy following frst-line geftinib treatment in non-small cell lung cancer patients harboring sensitive EGFR mutations. Clin Transl Oncol 17: 702-709, 2015.

3. Polanski J, Jankowska-Polanska B, Rosinczuk J, Chabowski M and Szymanska-Chabowska A: Quality of life of patients with lung cancer. Onco Targets Ther 9: 1023-1028, 2016.

4. Yan H, Fan HX, Song LH, Xie JC and Fan SF: Relationship between contrast-enhanced $\mathrm{CT}$ and clinicopathological characteristics and prognosis of non-small cell lung cancer. Oncol Res Treat 40: 516-522, 2017.

5. Facchinetti F, Pilotto S, Metro G, Baldini E, Bertolaccini L, Cappuzzo F, Delmonte A, Gasparini S, Inno A, Marchetti A, et al: Treatment of metastatic non-small cell lung cancer: 2018 guidelines of the Italian association of medical oncology (AIOM). Tumori 105 (5 Suppl): S3-S14, 2019.

6. Stinchcombe TE, Borghaei H, Barker SS, Treat JA and Obasaju C: Pemetrexed with platinum combination as a backbone for targeted therapy in non-small-cell lung cancer. Clin Lung Cancer 17: 1-9, 2016.
7. Al-Saleh K, Quinton C and Ellis PM: Role of pemetrexed in advanced non-small-cell lung cancer: Meta-analysis of randomized controlled trials, with histology subgroup analysis. Curr Oncol 19: e9-e15, 2012.

8. Paz-Ares LG, de Marinis F, Dediu M, Thomas M, Pujol JL, Bidoli P, Molinier O, Sahoo TP, Laack E, Reck M, et al: PARAMOUNT: Final overall survival results of the phase III study of maintenance pemetrexed versus placebo immediately following induction treatment with pemetrexed plus cisplatin for advanced nonsquamous non-small-cell lung cancer. J Clin Oncol 31: 2895-2902, 2013.

9. Fuld AD, Dragnev KH and Rigas JR: Pemetrexed in advanced non-small-cell lung cancer. Expert Opin Pharmacother 11: 1387-1402, 2010

10. Li J, Yen C, Liaw D, Podsypanina K, Bose S, Wang SI, Puc J, Miliaresis C, Rodgers L, McCombie R, et al: PTEN, a putative protein tyrosine phosphatase gene mutated in human brain, breast, and prostate cancer. Science 275: 1943-1947, 1997.

11. Carrera AC and Anderson R: The cell biology behind the oncogenic PIP3 lipids. J Cell Sci 132: pii: jcs228395, 2019.

12. Stambolic V, Suzuki A, de la Pompa JL, Brothers GM, Mirtsos C, Sasaki T, Ruland J, Penninger JM, Siderovski DP and Mak TW: Negative regulation of PKB/Akt-dependent cell survival by the tumor suppressor PTEN. Cell 95: 29-39, 1998.

13. Bufu T, Di X, Yilin Z, Gege L, Xi C and Ling W: Celastrol inhibits colorectal cancer cell proliferation and migration through suppression of MMP3 and MMP7 by the PI3K/AKT signaling pathway. Anticancer Drugs 29: 530-538, 2018.

14. Kechagioglou P, Papi RM, Provatopoulou X, Kalogera E, Papadimitriou E, Grigoropoulos P, Nonni A, Zografos G, Kyriakidis DA and Gounaris A: Tumor suppressor PTEN in breast cancer: Heterozygosity, mutations and protein expression. Anticancer Res 34: 1387-1400, 2014.

15. Pérez-Ramírez C, Cañadas-Garre M, Molina MÁ, Faus-Dáder MJ and Calleja-Hernández MÁ: PTEN and PI3K/AKT in non-small-cell lung cancer. Pharmacogenomics 16: 1843-1862, 2015.

16. Ni S, Wang H, Zhu X, Wan C, Xu J, Lu C, Xiao L, He J, Jiang C, Wang W and He Z: CBX7 suppresses cell proliferation, migration, and invasion through the inhibition of PTEN/Akt signaling in pancreatic cancer. Oncotarget 8: 8010-8021, 2017.

17. Jin X, Xu Z, Fan R, Wang C, Ji W, Ma Y, Cai W, Zhang Y, Yang N, Zou S, et al: HO-1 alleviates cholesterol-induced oxidative stress through activation of Nrf2/ERK and inhibition of PI3K/AKT pathways in endothelial cells. Mol Med Rep 16: 3519-3527, 2017.

18. Livak KJ and Schmittgen TD: Analysis of relative gene expression data using real-time quantitative PCR and the 2(-Delta Delta C(T)) method. Methods 25: 402-408, 2001.

19. Acheampong E, Spencer I, Lin W, Ziman M, Millward M and Gray E: Is the blood an alternative for programmed cell death ligand 1 assessment in non-small cell lung cancer? Cancers (Basel) 11 pii: E920, 2019.

20. Masters GA, Temin S, Azzoli CG, Giaccone G, Baker S Jr, Brahmer JR, Ellis PM, Gajra A, Rackear N, Schiller JH, et al: Systemic therapy for stage IV non-small-cell lung cancer: American society of clinical oncology clinical practice guideline update. J Clin Oncol 33: 3488-3515, 2015.

21. Rothbart SB, Racanelli AC and Moran RG: Pemetrexed indirectly activates the metabolic kinase AMPK in human carcinomas. Cancer Res 70: 10299-10309, 2010.

22. Steck PA, Pershouse MA, Jasser SA, Yung WK, Lin H, Ligon AH, Langford LA, Baumgard ML, Hattier T, Davis T, et al: Identification of a candidate tumour suppressor gene, MMAC1, at chromosome 10q23.3 that is mutated in multiple advanced cancers. Nat Genet 15: 356-362, 1997.

23. Tibarewal P, Zilidis G, Spinelli L, Schurch N, Maccario H, Gray A, Perera NM, Davidson L, Barton GJ and Leslie NR: PTEN protein phosphatase activity correlates with control of gene expression and invasion, a tumor-suppressing phenotype, but not with AKT activity. Sci Signal 5: ra18, 2012.

24. Andrés-Pons A, Gil A, Oliver MD, Sotelo NS and Pulido R: Cytoplasmic p27Kip1 counteracts the pro-apoptotic function of the open conformation of PTEN by retention and destabilization of PTEN outside of the nucleus. Cell Signal 24: 577-587, 2012.

25. Luna S, Mingo J, Aurtenetxe O, Blanco L, Amo L, Schepens J, Hendriks WJ and Pulido R: Tailor-made protein tyrosine phosphatases: In vitro site-directed mutagenesis of PTEN and PTPRZ-B. Methods Mol Biol 1447: 79-93, 2016.

26. Huang J and Manning BD: A complex interplay between Akt, TSC2 and the two mTOR complexes. Biochem Soc Trans 37: 217-222, 2009. 
27. Yu H, Qiu Y, Pang X, Li J, Wu S, Yin S, Han L, Zhang Y, Jin C, Gao $\mathrm{X}$, et al: Lycorine promotes autophagy and apoptosis via TCRP1/Akt/mTOR axis inactivation in human hepatocellular carcinoma. Mol Cancer Ther 16: 2711-2723, 2017.

28. Hwang KE, Kim YS, Jung JW, Kwon SJ, Park DS, Cha BK, $\mathrm{Oh} \mathrm{SH}$, Yoon KH, Jeong ET and Kim HR: Inhibition of autophagy potentiates pemetrexed and simvastatin-induced apoptotic cell death in malignant mesothelioma and non-small cell lung cancer cells. Oncotarget 6: 29482-29496, 2015.

29. Wang X, Simpson ER and Brown KA: p53: Protection against tumor growth beyond effects on cell cycle and apoptosis. Cancer Res 75: 5001-5007, 2015.

30. Matsuda S, Nakagawa Y, Kitagishi Y, Nakanishi A and Murai T: Reactive oxygen species, superoxide dimutases, and PTEN-p53-AKT-MDM2 signaling loop network in mesenchymal stem/stromal cells regulation. Cells 7: pii: E36, 2018.

31. Hollstein M, Sidransky D, Vogelstein B and Harris CC: p53 mutations in human cancers. Science 253: 49-53, 1991.

32. Lane DP: Cancer. p53, guardian of the genome. Nature 358: 15-16, 1992.

33. Li Y,Guessous F, Kwon S,Kumar M,Ibidapo O,Fuller L, Johnson E, Lal B, Hussaini I, Bao Y, et al: PTEN has tumor-promoting properties in the setting of gain-of-function p53 mutations. Cancer Res 68: 1723-1731, 2008.

34. Yu J, Zhang L, Hwang PM, Kinzler KW and Vogelstein B: PUMA induces the rapid apoptosis of colorectal cancer cells. Mol Cell 7: 673-682, 2001

35. Sheikh MS, Burns TF, Huang Y, Wu GS, Amundson S, Brooks KS Fornace AJ Jr and el-Deiry WS: p53-dependent and -independent regulation of the death receptor KILLER/DR5 gene expression in response to genotoxic stress and tumor necrosis factor alpha. Cancer Res 58: 1593-1598, 1998.

36. Peña-Blanco A and García-Sáez AJ: Bax, Bak and beyond-mitochondrial performance in apoptosis. FEBS J 285: 416-431, 2018.

37. Cosentino K and García-Sáez AJ: BAX and Bak pores: Are we closing the circle? Trends Cell Biol 27: 266-275, 2017.
38. Miyashita T and Reed JC: Tumor suppressor p53 is a direct transcriptional activator of the human bax gene. Cell 80: 293-299, 1995.

39. Ugarte-Uribe B and García-Sáez AJ: Apoptotic foci at mitochondria: In and around Bax pores. Philos Trans R Soc Lond B Biol Sci 372: pii: 20160217, 2017.

40. Villanova L, Careccia S, De Maria R and Fiori ME: Micro-economics of apoptosis in cancer: ncRNAs modulation of BCL-2 family members. Int J Mol Sci 19: pii: E958, 2018.

41. Letai A, Sorcinelli MD, Beard C and Korsmeyer SJ: Anti-apoptotic BCL-2 is required for maintenance of a model leukemia. Cancer Cell 6: 241-249, 2004.

42. Lessene G, Czabotar PE and Colman PM: BCL-2 family antagonists for cancer therapy. Nat Rev Drug Discov 7: 989-1000, 2008.

43. Delbridge AR, Grabow S, Strasser A and Vaux DL: Thirty years of BCL-2: Translating cell death discoveries into novel cancer therapies. Nat Rev Cancer 16: 99-109, 2016.

44. Levine AJ and Puzio-Kuter AM: The control of the metabolic switch in cancers by oncogenes and tumor suppressor genes. Science 330: 1340-1344, 2010.

45. Pavlova NN and Thompson CB: The emerging hallmarks of cancer metabolism. Cell Metab 23: 27-47, 2016.

46. Wang R and Green DR: Metabolic checkpoints in activated T cells. Nat Immunol 13: 907-915, 2012.

47. Chen JQ and Russo J: Dysregulation of glucose transport, glycolysis, TCA cycle and glutaminolysis by oncogenes and tumor suppressors in cancer cells. Biochim Biophys Acta 1826: 370-384, 2012.

This work is licensed under a Creative Commons Attribution-NonCommercial-NoDerivatives 4.0 International (CC BY-NC-ND 4.0) License. 